\title{
SPECT for Differential Diagnosis of Dementia and Correlation of rCBF with Cognitive Impairment
}

\author{
Alicia Osimani, Masanori Ichise, Dae-Gyun Chung, Janice M. Pogue and \\ Morris Freedman
}

\begin{abstract}
Tc}-\mathrm{HM}-\mathrm{PAO}$ single photon emission computed tomography (SPECT) was used to image 30 patients referred for the assessment of dementia. SPECT images revealed various patterns of regional cerebral perfusion (rCBF) in the subgroups of patients with the clinical diagnoses of Alzheimer's disease (AD, $n=14)$, Pick's disease $(n=1)$, and multi-infarct dementia $(n=7)$. In three patients, SPECT clarified the clinical differential diagnostic possibilities. Using a relative rCBF quantification technique, the relationship between specific cognitive impairments and rCBF in the AD patients was determined. There was a significant correlation between language impairment and left hemisphere hypoperfusion, whereas, apraxia correlated with hypoperfusion in the left parietal region. Thus, HMPAO SPECT is useful as an aid in the differential diagnosis of dementia and the technique of relative rCBF quantification with SPECT may contribute to the understanding of the clinico-anatomical relations of cognitive deficits in dementia.
\end{abstract}

\begin{abstract}
Résumé: Le SPECT dans le diagnostic différentiel de la démence et la corrélation de la rCBF avec la détérioration cognitive. Nous avons utilisé la tomographie à émetteur gamma au ${ }^{99 \mathrm{~m} T \mathrm{~T}-H M-P A O}$ (SPECT) pour investiguer 30 patients référés pour évaluation d'une démence. L'imagerie par le SPECT a montré différents schémas de perfusion cérébrale régionale ( $\mathrm{rCBF}$ ) chez des sous-groupes de patients avec un diagnostic clinique de maladie d'Alzheimer $(A D, n=14)$, maladie de Pick $(n=1)$ et démence par infarctus multiples $(n=7)$. Chez trois patients, le SPECT a clarifié les possibilités quant au diagnostic différentiel. Au moyen d'une technique de quantification relative de la rCBF, nous avons déterminé quelle est la relation entre des altérations cognitives spécifiques et la rCBF chez les patients porteurs d'une maladie d'Alzheimer. Il y avait une corrélation significative entre l'altération du langage et l'hypoperfusion de l'hémisphère gauche, alors que l'apraxie était corrélée à l'hypoperfusion de la région pariétale gauche. Le SPECT par HM-PAO aide au diagnostic différentiel de la démence et la technique de quantification relative de la rCBF au moyen du SPECT peut contribuer à la compréhension des relations clinicoanatomiques des déficits cognitifs dans la démence.
\end{abstract}

Can. J. Neurol. Sci. 1994; 21: 104-111

Whereas $x$-ray computed tomography (CT) and magnetic resonance imaging (MRI) have revolutionized the evaluation of patients with structural brain damage, these techniques have remained of limited value in the assessment of dementia due to neurodegenerative disease. For the latter, the use of functional neuro-imaging procedures such as single photon emission computed tomography (SPECT) and positron emission tomography (PET) have proven to be more informative for both diagnosis and clinico-anatomical correlation. These techniques can determine various physiological parameters of the brain by employing different radioactive tracers. With SPECT, only regional cerebral blood flow (rCBF) can currently be evaluated in clinical practice, but other tracers including receptor imaging agents are being developed. ${ }^{1.2}$ Flow and metabolism, however, are coupled in most chronic pathological states and rCBF SPECT demonstrates comparable images to those obtained by
PET using metabolic tracers. ${ }^{3}$ In Alzheimer's disease (AD), for example, both SPECT and PET show characteristic perfusion/metabolic deficits in the temporo-parietal regions. In contrast CT and MRI are either normal or demonstrate only diffuse atrophy. ${ }^{4-15}$

Although the spatial resolution attainable with PET has generally been superior to that of SPECT, this difference is now diminishing. Recently introduced neuro-dedicated SPECT systems have spatial resolutions approaching those of PET

From the Rotman Research Institute of Baycrest Centre for Geriatric Care (A.O. J.M.P., M.F.); Behavioral Neurology Program, Baycrest Hospital (A.O., M.F.); Division of Neurology (A.O., M.F.); Department of Radiology (Division of Nuclear Medicine) (M.l., D-G.C.), Mount Sinai Hospital, University of Toronto.

RECEIVED SEPTEMBER 8, 1993. ACCEPTED IN FINAL FORM NOVEMBER 13, 1993.

Reprint requests to: Dr. Morris Freedman, Baycrest Hospital, Room 4W36, 3560 Bathurst Street, Toronto, Ontario, Canada M6A 2E 
systems. A potential disadvantage of SPECT is the complexity involved in performing absolute quantification measurements. However, several attempts have been made to develop relative quantification techniques using cerebellar perfusion as a reference $^{12,16-18}$ for comparison to other brain regions since the cerebellum is relatively spared in most neurodegenerative disorders. ${ }^{19}$ A significant advantage of SPECT over PET, however, is that SPECT is less expensive than PET and hence is more readily available. Thus it is important to determine the usefulness of SPECT and to define its role in the diagnosis of cognitive disorders. Recent evidence suggests that rCBF SPECT can relate specific types of cognitive impairment to selective regional perfusion deficits. ${ }^{20-22}$

We report here a retrospective survey of clinical, CT, and SPECT findings in 30 patients referred for the assessment of dementia. The aim was to determine the relationship between clinical diagnosis and rCBF deficits, as well as to study the clinico-anatomical relationship between specific types of cognitive impairment and quantified regional perfusion deficits.

\section{METHODS}

The subjects consisted of 18 in-patients and 12 out-patients referred for assessment to the Behavioral Neurology Program at Baycrest Hospital, Toronto. Eight normal control (NC) subjects (all right-handed, 4 males and 4 females, age range 61 to 74 years, mean $66 \pm 5$ years) were selected from a group of subjects who were recruited by newspaper advertisement. They were screened to exclude any history of neuropsychiatric disorders, substance abuse, or head trauma. The NC project was granted ethical approval by the Human Subjects Review Committee of the University of Toronto. All patients were evaluated under the supervision of one neurologist (MF). Thus the assessment tools and diagnostic criteria were the same for all subjects. The data collected included age, sex, duration of disease and the mental status findings. The latter were based upon bedside tests of memory, language, ideomotor praxis, visuospatial performance, manipulation of acquired knowledge, and frontal lobe function. The mental status findings were translated into scores of 3,2,1 and 0 representing no, mild, moderate, and severe deficits, respectively. Measures of the general neurological examination included documentation of focal pyramidal and extrapyramidal signs, as well as sensory deficits.

The clinical diagnoses used in this study were the ones made prior to the SPECT imaging. In some cases there was a single diagnosis, whereas in others there was a differential diagnosis (eg., AD vs. multi-infarct dementia). Dementia was defined according to the criteria of Cummings and Benson ${ }^{23}$ as an acquired persistent impairment of intellectual function with compromise in at least three of the following spheres of mental activity: language, memory, visuospatial skills, emotion or personality and cognition (abstraction, calculation, judgment, etc.). All AD patients met NINCDS-ADRDA criteria for probable AD. ${ }^{24}$ All MID patients had a score of greater than 3 on the Modified Hachinski Ischemic Scale. ${ }^{25}$ The severity of dementia was assessed by activities of daily living function and the scores on tests of language, memory, and manipulation of acquired knowledge.

\section{[99mTc] HM-PAO SPECT Study}

After informed consent was obtained, each subject underwent $\left[{ }^{99 \mathrm{~m} T c}\right.$ ]HM-PAO brain SPECT as follows: $500 \mathrm{mg}$ of potassium perchlorate was given by mouth to reduce parotid gland uptake of tracer activity. $\left.{ }^{99 \mathrm{~m}} \mathrm{Tc}\right] \mathrm{HM}-\mathrm{PAO}$ was prepared according to the manufacturer's instructions, and within $30 \mathrm{~min}$ utes, $20 \mathrm{mCi}(740 \mathrm{MBq})$ of [ $\left.{ }^{99 \mathrm{~m}} \mathrm{Tc}\right] \mathrm{HM}-\mathrm{PAO}$ were injected intravenously in a quiet room with the subject's eyes open. Ten to 15 minutes later, SPECT imaging was performed using a truncated head rotating gamma camera (Elscint 409 AG) interfaced to a dedicated computer (Elscint PSI). We used a specially designed adjustable head holder to ensure that the camera face was perpendicular to the subject's orbito-meatal (OM) line at the starting position. Sixty 25 second images were obtained through a $360^{\circ}$ circular revolution using a high resolution parallel hole collimator. The radius of rotation was $14 \mathrm{~cm}$ or less. The full width at half maximum (FWHM) of the system at the centre was approximately $14 \mathrm{~mm}$. A total of 2.5-6.0 million counts were collected. The data were acquired in word mode on a $64 \times 64$ matrix, normalized to byte mode, and corrected for non-uniformity according to Elscint specifications. One pixel-thick $(7 \mathrm{~mm})$ transaxial slices were reconstructed parallel to the $O M$ line using a modified Hanning back projection filter. A magnification zoom of 1.8 was used during reconstruction. The first order Chang method of attenuation correction was employed. ${ }^{26}$ The transaxial data were then reoriented and reconstructed in the one-pixel thick coronal and sagittal planes. Each set of transaxial, sagittal and coronal images was normalized to the average counts per pixel in the cerebellar hemispheres. These images were recorded on film, and visually assessed by a qualified nuclear medicine physician (MI), who was blinded to the clinical data, as follows: first the images were assessed for the technical adequacy. Then each study was assessed to describe rCBF as normal, decreased, or increased, with focal, or diffuse, involvement. Perfusion abnormalities involving more than two contiguous cerebral lobes were classified as diffuse involvement, and abnormal perfusion localized within a cerebral lobe without contiguous involvement of adjacent lobes was classified as focal involvement.

A modification of methods of Johnson et al..$^{27}$ and Cohen et al. ${ }^{28}$ was used for semiquantitative analysis of the SPECT data. Transaxial slices parallel to the $\mathrm{OM}$ line were chosen to include upper and lower limits of the brain, and these were extrapolated using a software program to a constant set of 12 images for each study. We systematically matched well-defined anatomical landmarks on these SPECT images to a template (Figure 1) prepared from a tomographic neuroanatomical atlas. ${ }^{29}$ We manually placed square regions of interest (ROIs, $12 \times 12 \mathrm{~mm}$ ) over 6 regions in each fontal lobe, 2 regions in each temporal lobe, 4 regions in each parietal lobe, 2 regions in each occipital lobe, 1 region in each basal ganglia, and 1 region in each cerebellar hemisphere (Figure 1). Cortical/cerebellar ratios (referred to simply as rCBF ratios hereafter) were calculated using the average of the counts of right and left cerebellar ROIs as the denominator. Thus we obtained a total of $30 \mathrm{rCBF}$ ratios in each study.

\section{Statistical Analysis}

We used a commercial software package by BMDP Statistical Software Inc. (1989). The rCBF ratios were tested for normality by calculating $w$ statistics. Two tailed Student's $t$ tests 


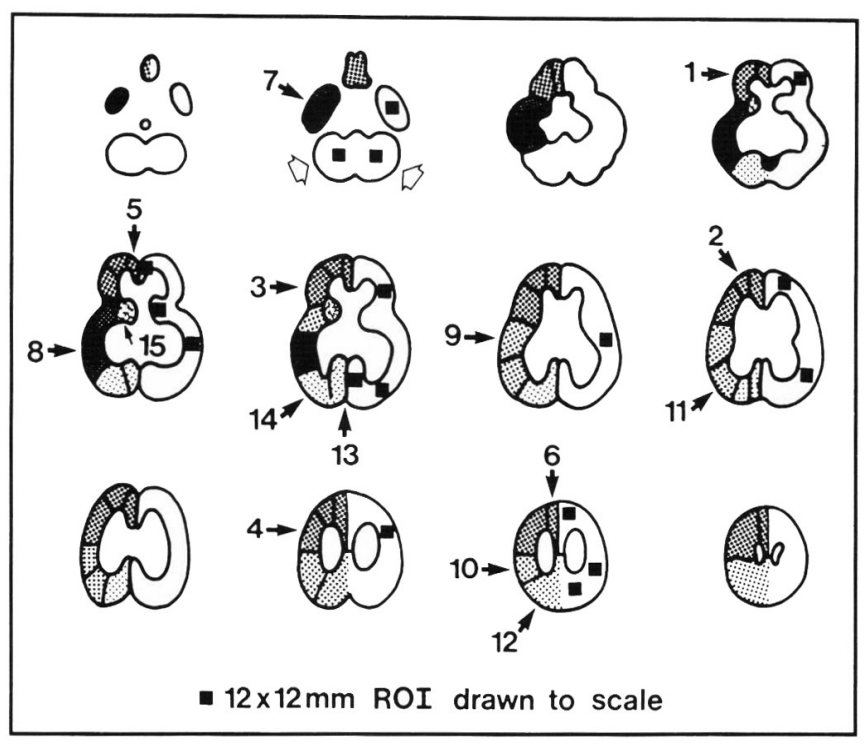

Figure 1: A neuroanatomical template and ROIs used for relative quantification.

On a tracing of 12 transaxial images of a normal control subject, major neuroanatomical landmarks were identified by reference to a tomographic atlas. 1-15 refer to hemispheric regional divisions in which ROls are placed as shown by black squares in the contralateral hemisphere. The white arrows show cerebellar ROIs.

FRONTAL LOBE

1. AIF (Anterior-Inferior Frontal)

2. ASF (Anterior-Superior Frontal)

3. PIF (Posterior-Inferior Frontal)

4. PSF (Posterior-Superior Frontal)

5. MIF (Medial-Inferior Frontal)

6. MSF (Medial-Superior Frontal)

\section{TEMPORAL LOBE}

7. AIT (Anterior-Inferior Temporal)

8. PST (Posterior-Superior Temporal)

PARIETAL LOBE

9. AIP (Anterior-Inferior Parietal)

10. ASP (Anterior-Superior Parietal)

II. PIP (Posterior-Inferior Parietal)

12. PSP (Posterior-Superior Parietal)

\section{OCCIPITAL LOBE}

13. MOC (Medial Occipital)

14. LOC (Lateral Occipital)

BASAL GANGLIA

15. BGA (Basal Ganglia)

were performed to compare the AD group with the NC group. Global average values of the $30 \mathrm{rCBF}$ ratios and individual rCBF ratios were used for this comparison. Because group vs. group comparisons may not reveal individual abnormalities when abnormal regions vary from subject to subject as seen in the MID group, we also compared the regional values for individual dementia subjects with the mean values for the NC group. Thirty individual rCBF ratios and hemispheric average values were correlated with the clinical data using Pearson correlation coefficients. Given the large number of variables, no correction for multiple comparisons was made in this study.

\section{ReSULTS}

\section{Visual Interpretation of SPECT Images}

All 38 SPECT studies were visually judged to be technically adequate. In the NC group, 7 subjects showed homogeneous uptake of the radiopharmaceutical throughout the grey matter with greatest activity in the cerebellum followed by the medial occipital lobe. Basal ganglia activity equalled the adjacent cerebral cortical activity. The remaining one subject showed mildly decreased perfusion in the frontal lobes. The demographic data, clinical diagnoses and visual interpretation of SPECT images for the 30 dementia patients are summarized in Table 1 . Of 26 patients with clinical evidence of dementia (considered "mild" in 16 and "moderate" in 10 patients), twenty-five showed perfusion deficits on visual interpretation. The one demented patient with a normal SPECT scan suffered anoxic encephalopathy secondary to a cardiac arrest. The remaining four patients (cases 27 to 30 ), also referred to the clinic for the assessment of dementia, were found not to be demented according to the criteria of Cummings and Benson. ${ }^{23}$ They showed only poor attention and concentration without impairment in other cognitive functions such as memory. They each had a normal SPECT scan.

The patients with AD had SPECT scans which generally showed hypoperfusion of the posterior temporo-parietal regions bilaterally. However, four patients in this group showed asymmetrical involvement, with more pronounced deficits in the left hemisphere (Figure 2) in three patients, and more right sided deficits in one subject. This asymmetrical perfusion deficits have been reported by previously both PET and SPECT studies of Alzheimer's disease. ${ }^{21,30,31}$ In seven of these patients, the rCBF defects also involved the frontal lobe, correlating well with frontal signs on mental status examination. These findings are consistent with reports obtained from pathological studies of AD. ${ }^{32}$ One patient, case 18, died and had an autopsy. The neuropathological findings confirmed the diagnosis of AD. CT scans of these AD patients showed very mild to moderate diffuse cerebral cortical atrophy without any specific patterns.

In the MID group, asymmetrical multiple focal deficits constituted a characteristic pattern which is consistent with previous studies using both PET ${ }^{11,33-35}$ and SPECT. ${ }^{5-7.9,10,12,14,21}$ Figure 3A shows transaxial SPECT images of one MID patient (Case 5). Multiple focal deficits were seen in both hemispheres (a-f).

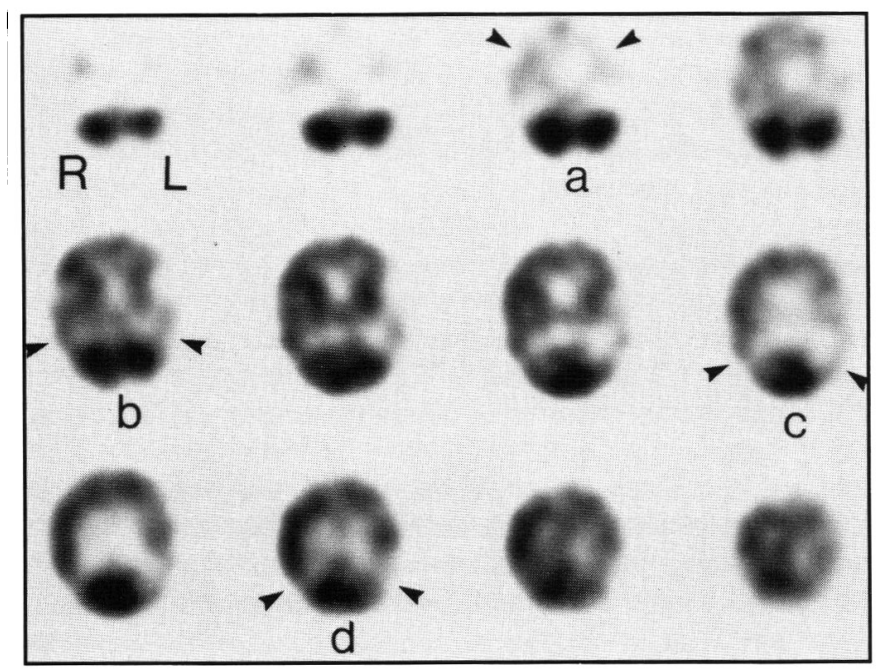

Figure 2: SPECT imaging (transaxial view) of a 64-year-old male $A D$ patient (Case 17). Reduction of cortical perfusion is clearly seen in the temporal lobes bilaterally $(a, b)$ and extending into the parietal lobes $(c, d)$. The perfusion deficits are more pronounced on the left side. 
Table 1. Clinical and SPECT Data.

\begin{tabular}{|c|c|c|c|c|c|c|}
\hline Case & Age & Sex & $\begin{array}{l}\text { Duration } \\
\text { in Months }\end{array}$ & $\begin{array}{l}\text { Clinical } \\
\text { Diagnosis }\end{array}$ & Severity & $\begin{array}{l}\text { SPECT } \\
\text { Deficits }\end{array}$ \\
\hline 1 & 78 & $\mathbf{M}$ & 36 & MID & Mild & Multi focal \\
\hline 2 & 75 & $\mathbf{M}$ & 12 & MID & Mild & Multi focal \\
\hline 3 & 68 & M & 12 & MID & Mild & Multi focal \\
\hline 4 & 69 & $F$ & 12 & MID & Moderate & Multi focal \\
\hline 5 & 81 & $\mathrm{~F}$ & 12 & MID & Moderate & Multi focal \\
\hline 6 & 60 & $\mathbf{M}$ & 24 & MID & Moderate & Multi focal \\
\hline 7 & 59 & $\mathbf{M}$ & 24 & MID vs. AD & Moderate & Multi focal \\
\hline 8 & 62 & $\mathbf{M}$ & 36 & MID vs. AD & Moderate & $\begin{array}{l}\text { Bilateral } \\
\text { Frontotemporal } \\
\text { Parietal }\end{array}$ \\
\hline 9 & 73 & $\mathbf{M}$ & 36 & $A D$ & Mild & $\begin{array}{l}\text { Bilateral } \\
\text { Temporoparietal }\end{array}$ \\
\hline 10 & 74 & $\mathrm{~F}$ & 9 & $A D$ & Mild & $\begin{array}{l}\text { Bilateral } \\
\text { Frontotemporal } \\
\text { Parietal }\end{array}$ \\
\hline 11 & 71 & $\mathrm{~F}$ & 72 & $A D$ & Mild & $\begin{array}{l}\text { Bilateral } \\
\text { Frontotemporal } \\
\text { Parietal }\end{array}$ \\
\hline 12 & 58 & $\mathrm{~F}$ & 48 & $A D$ & Mild & $\begin{array}{l}\text { Bilateral } \\
\text { Temporoparietal }\end{array}$ \\
\hline 13 & 72 & $\mathrm{~F}$ & 24 & $A D$ & Mild & $\begin{array}{l}\text { Bilateral } \\
\text { Frontotemporal } \\
\text { Parietal }\end{array}$ \\
\hline 14 & 55 & $\mathrm{~F}$ & 30 & $A D$ & Mild & $\begin{array}{l}\text { Bilateral } \\
\text { Frontotemporal } \\
\text { Parietal }\end{array}$ \\
\hline 15 & 67 & $\mathbf{M}$ & 60 & $A D$ & Mild & $\begin{array}{l}\text { Left } \\
\text { Frontotemporal } \\
\text { Parietal }\end{array}$ \\
\hline 16 & 62 & $\mathrm{~F}$ & 24 & $A D$ & Mild & $\begin{array}{l}\text { Right } \\
\text { Temporoparietal }\end{array}$ \\
\hline 17 & 64 & $\mathbf{M}$ & 72 & $A D$ & Moderate & $\begin{array}{l}\text { Left } \\
\text { Temporoparietal }\end{array}$ \\
\hline 18 & 70 & $\mathbf{M}$ & 24 & $\mathrm{AD}^{*}$ & Moderate & $\begin{array}{l}\text { Bilateral } \\
\text { Temporoparietal }\end{array}$ \\
\hline 19 & 56 & $M$ & 36 & $A D$ & Moderate & $\begin{array}{l}\text { Left } \\
\text { Temporoparietal }\end{array}$ \\
\hline 20 & 69 & $\mathbf{M}$ & 60 & $\begin{array}{l}\text { AD vs. } \\
\text { Progressive } \\
\text { Aphasia }\end{array}$ & Mild & $\begin{array}{l}\text { Bilateral Frontal } \\
\text { \& Left Peri- } \\
\text { sylvian }\end{array}$ \\
\hline 21 & 50 & M & 36 & Pick’s & Moderate & $\begin{array}{l}\text { Left Frontal } \\
\text { \& Left Anterior } \\
\text { Temporal }\end{array}$ \\
\hline 22 & 82 & $\mathrm{~F}$ & 24 & $\begin{array}{l}\text { AD vs. } \\
\text { Pick's }\end{array}$ & Mild & $\begin{array}{l}\text { Left } \\
\text { Frontotemporal } \\
\text { Parietal }\end{array}$ \\
\hline 23 & 61 & $\mathrm{~F}$ & 48 & $\begin{array}{l}\text { Collagen } \\
\text { disease }\end{array}$ & Mild & Bilateral Frontal \\
\hline 24 & 29 & $\mathbf{M}$ & 12 & MS & Mild & White Matter \\
\hline 25 & 36 & $\mathbf{M}$ & 6 & Huntington's & Mild & $\begin{array}{l}\text { Bilateral Frontal } \\
\text { \& Basal Ganglia }\end{array}$ \\
\hline 26 & 58 & M & 1 & $\begin{array}{l}\text { Post } \\
\text { Anoxic } \\
\text { Encephalopatl }\end{array}$ & $\begin{array}{l}\text { Moderate } \\
\text { thy }\end{array}$ & Normal \\
\hline 27 & 78 & $\mathbf{M}$ & 60 & Parkinson's & $\begin{array}{l}\text { Non- } \\
\text { demented }\end{array}$ & Normal \\
\hline 28 & 79 & F & 36 & Parkinson's & $\begin{array}{l}\text { Non- } \\
\text { demented }\end{array}$ & Normal \\
\hline 29 & 71 & $\mathbf{F}$ & 6 & $\begin{array}{l}\text { Drug } \\
\text { Intoxication }\end{array}$ & $\begin{array}{l}\text { Non- } \\
\text { demented }\end{array}$ & Normal \\
\hline 30 & 60 & M & 96 & $\begin{array}{l}\text { Psychotic } \\
\text { depression }\end{array}$ & $\begin{array}{l}\text { Non- } \\
\text { demented }\end{array}$ & Normal \\
\hline
\end{tabular}

*Diagnosis of $\mathrm{AD}$ was confirmed at autopsy.
Figure 3B shows CT scan of the same MID patient. There was mild diffuse cortical atrophy and focal encaphalomalacia corresponding to the two SPECT perfusion defects. No other definite focal CT abnormalities were found. Seven MID patients showed a total of 37 focal perfusion deficits by SPECT, and 15 focal abnormalities consistent with old infarction by CT, including a normal CT in one patient who showed 4 focal SPECT perfusion defects.

The patient with a clinical diagnosis of Pick's disease (Case 21) showed markedly decreased perfusion in the left frontotemporal lobes, and mildly decreased perfusion in the right frontal and left parieto-occipital lobes (Figure 4A). This patient's CT scan showed minimal left frontal lobe atrophy (Figure 4B). This pattern was in contrast to the most marked perfusion deficits in the posterior temporo-parietal lobes in the $\mathrm{AD}$ group. Asymmetrical and most marked fronto-temporal lobar involvement in Pick's disease has been described by CT and PET studies with histopathological confirmation. ${ }^{36-39}$ The parietal and occipital lobes may be involved but to a much lesser degree. ${ }^{36}$

Patient 22, on the other hand, had a differential diagnosis of $A D$ versus Pick's disease. The SPECT images showed diffuse perfusion deficits bilaterally most marked in the left posterior temporo-parietal lobes. A diagnosis of AD was thus supported. Follow-up on this patient showed language and memory loss patterns more compatible with AD.

Although rCBF SPECT is more sensitive to cortical than subcortical deficits, SPECT images of a patient with multiple sclerosis (Case 24) did demonstrate hypoperfusion of white matter. There was an apparent enlargement of the lateral ventricles, as compared to their size on CT, due to decreased periventricular perfusion. Subcortical deficits were also demonstrated in the patient with suspected Huntington's disease (Case 25) and are consistent with the findings of Podreka et al. ${ }^{14}$ Sharp et al., ${ }^{7}$ on the other hand, found no SPECT abnormalities in four patients with Huntington's disease.

\section{Relative Quantification of SPECT Images}

The $\mathrm{rCBF}$ ratios of the $\mathrm{NC}$ and patient groups were normally distributed. The coefficients of variation in $\mathrm{rCBF}$ ratios among repeated determinations on the same subject in a single SPECT study averaged $3 \%$. Table 2 shows mean \pm SD rCBF ratios for 8 $\mathrm{NC}$ subjects and $14 \mathrm{AD}$ patients, and individual $\mathrm{rCBF}$ ratios of one MID patient (Case 5) and one Pick's disease patient (Case 21). Regions visually detected as showing decreased perfusion showed rCBF ratios below mean-ISD values of the NC group (Table 2). Compared with the NC group, the AD group showed significantly lower $\mathrm{rCBF}$ ratios, globally (NC: $0.862 \pm .041 \mathrm{vs}$. AD: $0.800 \pm 0.038 ; p<0.001$ ), and throughout multiple individual regions in the left frontal and temporo-parieto-occipital lobes bilaterally (Table 2). Marked rCBF reductions were found in the left superior parietal, left inferior parietal, right inferior parietal, and lateral occipital regions $(\mathrm{p}<0.001)$.

In the $\mathrm{AD}$ group, there was a significant correlation between language impairment and average left hemisphere hypoperfusion $(r=0.61, p<0.05)$. The test scores for "language" were based upon measures of word finding difficulty, naming to confrontation, paraphasia, and auditory comprehension. ${ }^{40}$ When individual ROIs within the left hemisphere were considered, the following areas correlated with language impairment: left temporal $(r=0.68, p<0.05)$ and left parietal region $(r=0.70$, 
$p<0.05)$. There was also a significant correlation between ideomotor limb praxis and the left parietal region $(\mathrm{r}=0.69, \mathrm{p}<$ $0.05)$. Significant associations found between individual neuropsychological test scores and rCBF ratios are shown in Table 3. There was no significant correlation between duration of disease or age of onset, and rCBF ratios.

\section{Discussion}

Our results suggest that SPECT can serve as an important diagnostic tool. Patients with AD showed perfusion deficits in the posterior temporo-parietal regions, even in cases of mild dementia. Although the literature regarding SPECT in mild AD is controversial, ${ }^{7,8.13,41}$ the conflicting results may reflect differences

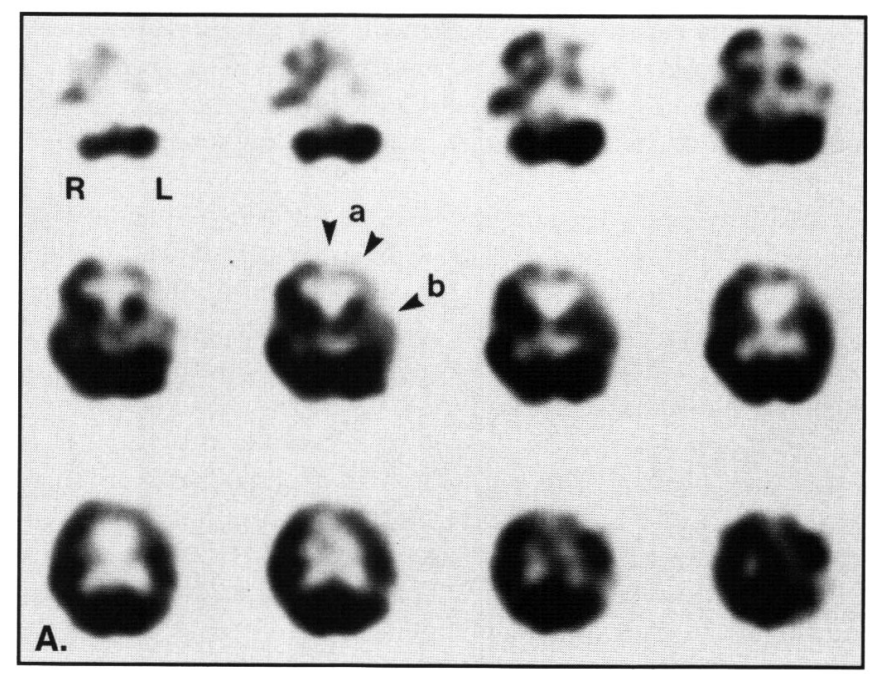

Figure 3A: SPECT imaging of (transaxial view) an 81-year-old female MID patient (Case 5). Multiple focal $r C B F$ deficits are seen asymmetrically involving both hemispheres: left posterior-superior parietal (a), right superior parietal (b), left lateral occipital (c), left peri-sylvian $(d)$, right posterior-superior frontal $(e)$, and left superior frontal $(f)$ regions. in methodology with respect to sample size and diagnostic criteria.

Our criteria were similar to those utilized by Sharp et al. ${ }^{7}$ who studied 47 dementia patients, including 14 subjects with $\mathrm{AD}$, diagnosed and classified according to the criteria of the third edition of the American Psychiatric Association Diagnostic and Statistical Manual. The Hachinski Ischemic Score $^{42}$ was used to discriminate between AD and MID. The extent of cognitive impairment was determined by a battery of neuropsychological tests. They also observed decreased perfusion on SPECT imaging in all patients with $A D$, including those with only mild cognitive deficits.

In Reed et al.' ${ }^{8}$ study of 21 patients with AD, the criteria for diagnosis were those of the NINCDS-ADRDA ${ }^{24}$ and the degree of severity was determined by the Mini-Mental State Exam (MMSE) as well as a modified version of the California Verbal Learning Test. However, their nine mildly impaired patients had a MMSE mean score of 26.6 which is above the lower limit of normal for the elderly population. Moreover, three of the patients showed only memory problems without impairment in any other area of cognition. Also three mildly and two moderately impaired patients had no SPECT abnormalities. The authors concluded that memory deficits, without other cognitive impairment, may be an early manifestation of AD before SPECT reveals any deficit. In a previous study of nine patients with AD, Jagust et al. ${ }^{10}$ used similar criteria. Among their mildly demented patients there was also one whose only cognitive deficit was memory. The nine patients showed temporo-parietal deficits in tracer uptake that were related to the severity of dementia. The results of the above studies cannot be compared to the present series in which patients with memory impairment without additional cognitive deficits were not considered demented. All patients with AD in our series had impairment in at least three cognitive areas, and this may account for the differences in results. Larger samples are necessary to unravel the question of sensitivity of rCBF SPECT to detect very early AD.

One of $8 \mathrm{NC}$ subjects showed mildly decreased perfusion in the frontal lobes on visual inspection compared with the

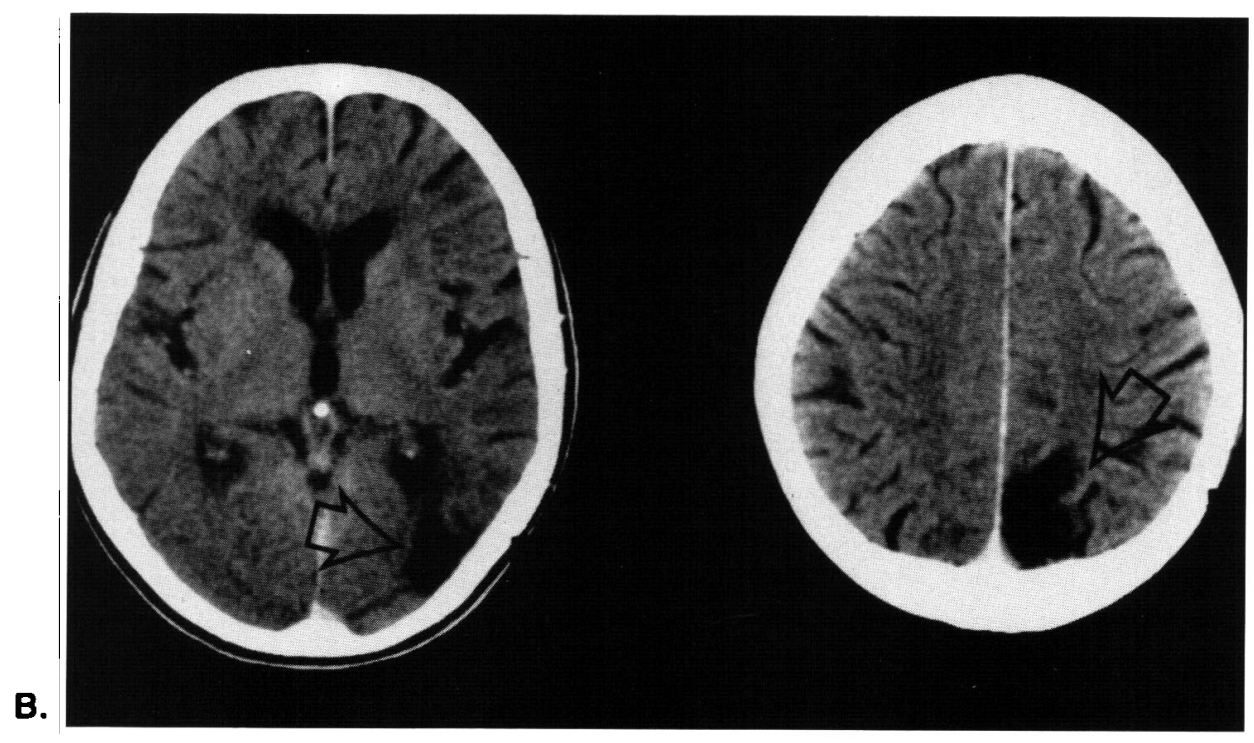

Figure 3B: CT scan of the same MID patient (selected 2 transaxial images). White arrows indicate focal encephalomalacia corresponding to the perfusion defects in left posterior-superior parietal $(a)$ and left lateral occipital $(c)$ regions. There is mild diffuse cortical atrophy. 


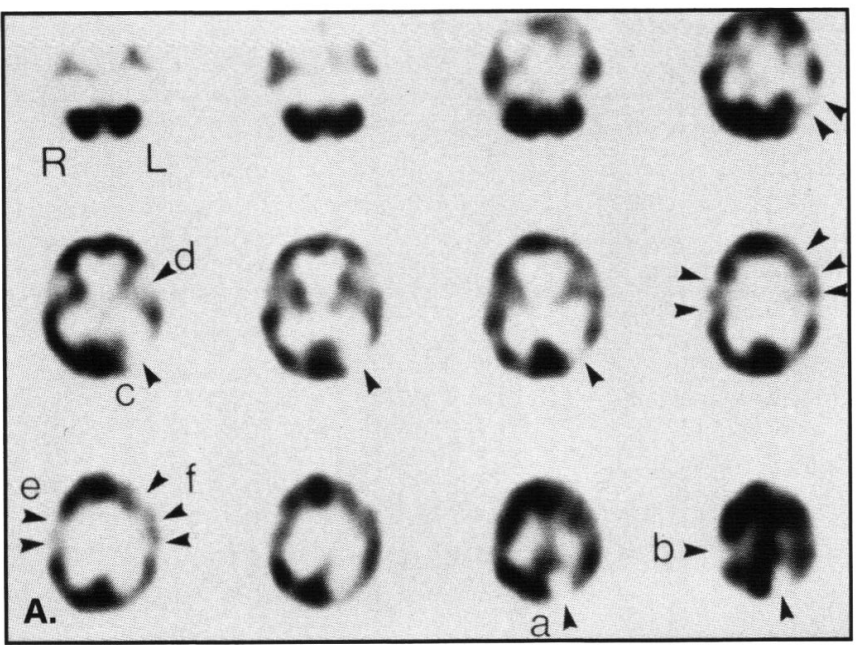

Figure 4A: SPECT imaging (transaxial view) of a 50-year-old male with Pick's disease (Case 2I). Markedly decreased cortical perfusion is seen in the left (a) frontal and (b) temporal lobes. Mild perfusion deficits are also seen in the right frontal and left parieto-occipital regions. In addition, there is decreased perfusion in the right cerebellum likely representing crossed cerebellar diaschesis.

remaining 7 subjects in the NC group. Physiological changes with normal aging as reported in the PET literature are somewhat inconsistent. A number of investigators have reported decreased metabolism in the anterior cerebral hemispheres, particularly the frontal lobes. However, when corrections for brain volume and atrophy are made, the effects of aging were no longer significant. ${ }^{43-48}$ Since no such corrections were made in our study, the above findings may be related to selective frontal lobar atrophy with normal aging. Thus it is important to assess the degree of atrophy in interpreting SPECT images. As in the patient with Pick's disease (Case 21), when perfusion deficits are disproportionately more pronounced than the CT evidence of atrophy, the rCBF SPECT constitutes a positive result.

It must be emphasized that rCBF SPECT demonstrates an anatomical profile of functional impairment and does not provide a definitive diagnosis. Therefore, cases in which the different diagnostic possibilities have similar anatomical profiles of perfusion deficits cannot be differentiated by SPECT. This was the situation in Case 20 in which a patient presented with a three year deterioration of speech, mild memory loss and moderate frontal signs. The clinical diagnosis was either progressive apha$\mathrm{sia}^{49}$ or atypical AD. The SPECT images showed marked hypoperfusion of the left anterior perisylvian area and left frontal lobe. The CT scan of this patient was unremarkable except for diffuse cortical atrophy. In this regard, MRI can rule out possible areas of infarction. Also in situations where perfusion deficits are diffuse due to neurodegenerative disorders, MRI may demonstrate foci of infarction which may coexist with neurodegenerative changes. ${ }^{7}$ In fact, cerebral infarction may involve large areas of the brain, giving an AD-like SPECT perfusion pattern. Thus interpretation of rCBF SPECT results of focal or diffuse involvement may be difficult in some situations without supporting morphological imaging and clinical information.

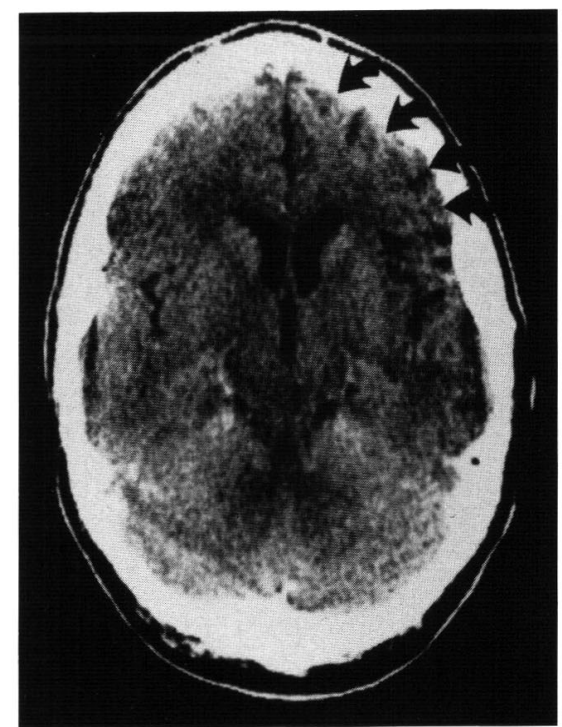

B.

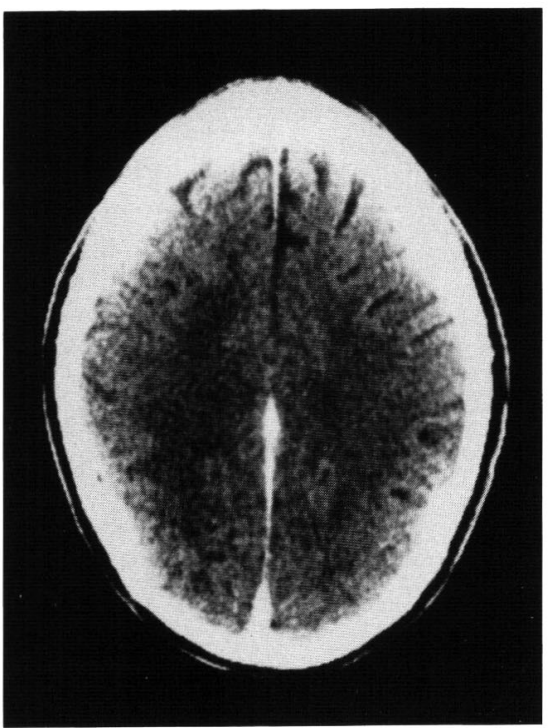

Figure 4B: CT scan of the same Pick's disease patient (selected 2 transaxial images). A minimal cortical atrophy is seen in the left frontal lobe (curved black arrows). This is in contrast to the rCBF SPECT, which shows unequivocal and more extensive perfusion deficits (Figure 4A).

Some patients with dementia may still have normal SPECT findings. Although Sharp et al. ${ }^{7}$ found good correspondence between $\mathrm{rCBF}$ SPECT findings and clinical diagnoses of $\mathrm{AD}$ and MID, patients with alcoholic dementia had normal scans. In the present series, the only severely demented patient who had a normal SPECT scan was the patient with post-anoxic encephalopathy. The cerebellum may be affected in both alcoholic dementia and in post-anoxic encephalopathy. Since the cerebellum is used as a reference point for normalizing $\mathrm{rCBF}$, the findings in these two syndromes may be artifactually normal. This is unlikely, however, since the patient had no cerebellar signs on clinical examination. Lee et al. ${ }^{50}$ reported SPECT findings during the acute stage of post-anoxic encephalopathy of decreased perfusion in the right parieto-occipital and left occipital regions. Our patient was scanned in the more chronic stages of 
Table 2. Mean \pm SD rCBF ratios for 8 normal controls and $14 \mathrm{AD}$ patients, and individual rCBF ratios for one MID patient (Case 5) and one Pick's disease patient (Case 21).

\section{RIGHT HEMISPHERE}

\begin{tabular}{lllll} 
Region & NC $(\mathbf{n}=8)$ & AD $(\mathbf{n}=14)$ & MID (Case 5) & Pick's (Case 21) \\
\hline Frontal & & & & \\
l. AIF & $.837 \pm .058$ & $.784 \pm .067$ & $.822(98 \%)$ & $.719(86 \%)^{\dagger \dagger}$ \\
2. ASF & $.814 \pm .059$ & $.809 \pm .062$ & $.844(104 \%)$ & $.703(86 \%)^{\dagger}$ \\
3. PIF & $.844 \pm .050$ & $.840 \pm .053$ & $.837(99 \%)$ & $.741(88 \%)^{\dagger \dagger}$ \\
4. PSF & $.836 \pm .065$ & $.807 \pm .051$ & $.755(90 \%)^{\dagger}$ & $.827(99 \%)$ \\
5. MIF & $.869 \pm .035$ & $.831 \pm .054$ & $.862(99 \%)$ & $.647(74 \%)^{\dagger \dagger}$ \\
6. MSF & $.824 \pm .069$ & $.810 \pm .069$ & $.873(106 \%)$ & $.649(78 \%)^{\dagger \dagger}$ \\
Temporal & & & & \\
7. AlT & $.778 \pm .068$ & $.709 \pm .066^{*}$ & $.809(104 \%)$ & $.715(92 \%)$ \\
8. PST & $.874 \pm .051$ & $.805 \pm .049^{* *}$ & $.876(100 \%)$ & $.807(92 \%)$ \\
Parietal & & & & \\
9. AIP & $.910 \pm .063$ & $.842 \pm .045^{* *}$ & $.881(97 \%)$ & $.846(93 \%)$ \\
10. ASP & $.888 \pm .069$ & $.812 \pm .057^{*}$ & $.838(94 \%)$ & $.873(99 \%)$ \\
11. PIP & $.879 \pm .041$ & $.796 \pm .044^{* * *}$ & $.863(98 \%)$ & $.970(110 \%)$ \\
12. PSP & $.876 \pm .027$ & $.824 \pm .054$ & $.910(104 \%)$ & $.875(100 \%)$ \\
Occipital & & & & \\
13. MOC & $.959 \pm .052$ & $.914 \pm .042^{*}$ & $.919(96 \%)$ & $.910(95 \%)$ \\
14. LOC & $.929 \pm .038$ & $.830 \pm .040^{* * *}$ & $.863(93 \%)^{\dagger}$ & $.894(96 \%)$ \\
Basal Ganglia & & & \\
15. BGA & $.836 \pm .047$ & $.835 \pm .040$ & $.850(102 \%)$ & $.803(96 \%)$ \\
\hline
\end{tabular}

\section{LEFT HEMISPHERE}

\begin{tabular}{lllll} 
Frontal & & & & \\
1. AIF & $.832 \pm .058$ & $.761 \pm .067^{*}$ & $.868(104 \%)$ & $.535(64 \%)^{\dagger \dagger}$ \\
2. ASF & $.820 \pm .064$ & $.790 \pm .080$ & $.742(90 \%)^{\dagger}$ & $.612(75 \%)^{\dagger \dagger}$ \\
3. PIF & $.846 \pm .054$ & $.807 \pm .086$ & $.735(87 \%)^{\dagger}$ & $.623(74 \%)^{\dagger \dagger}$ \\
4. PSF & $.842 \pm .085$ & $.779 \pm .071$ & $.743(88 \%)^{\dagger}$ & $.711(84 \%)^{\dagger}$ \\
5. MIF & $.872 \pm .033$ & $.817 \pm .065^{*}$ & $.894(103 \%)$ & $.518(59 \%)^{\dagger \dagger}$ \\
6. MSF & $.832 \pm .085$ & $.813 \pm .134$ & $.877(106 \%)$ & $.618(74 \%)^{\dagger+}$ \\
Temporal & & & & \\
7. AIT & $.737 \pm .093$ & $.664 \pm .082$ & $.773(105 \%)$ & $.485(66 \%)^{\dagger \dagger}$ \\
8. PST & $.861 \pm .052$ & $.762 \pm .084^{* *}$ & $.844(98 \%)$ & $.626(73 \%)^{\dagger \dagger}$ \\
Parietal & & & & \\
9. AIP & $.901 \pm .039$ & $.782 \pm .077^{* * *}$ & $.812(90 \%)^{\dagger+}$ & $.759(84 \%)^{\dagger \dagger}$ \\
10. ASP & $.884 \pm .069$ & $.753 \pm .074^{* * *}$ & $.890(101 \%)$ & $.794(80 \%)^{\dagger}$ \\
I1. PIP & $.860 \pm .036$ & $.741 \pm .074^{* * *}$ & $.820(95 \%)$ & $.795(92 \%)^{\dagger}$ \\
12. PSP & $.878 \pm .051$ & $.774 \pm .073^{* *}$ & $.642(74 \%)^{\dagger \dagger}$ & $.715(81 \%)^{\dagger \dagger}$ \\
Occipital & & & & \\
13. MOC & $.941 \pm .047$ & $.922 \pm .057$ & $.953(101 \%)$ & $.876(93 \%)^{\dagger}$ \\
14. LOC & $.922 \pm .026$ & $.803 \pm .054^{* * *}$ & $.613(66 \%)^{\dagger+}$ & $.792(86 \%)^{\dagger \dagger}$ \\
Basal Ganglia & & & \\
15. BGA & $.821 \pm .057$ & $.793 \pm .057$ & $.814(106 \%)$ & $.772(94 \%)$ \\
\hline
\end{tabular}

(percent of the normal control mean).

The significances of the differences between $A D$ and normal control group means are indicated as follows: $\left(^{*}\right) \mathrm{p}<0.05 ;\left(^{*}\right) \mathrm{p}<0.01 ;\left({ }^{* * *}\right) \mathrm{p}<$ 0.001

$\left(^{\dagger}\right)$ and $\left(^{+\dagger}\right)$ indicate values less than one and two SDs below the normal mean respectively.

For the description of the regions 1-15, refer to the legend in Figure 1.

hypoxic encephalopathy. Although we do not have a good explanation why the SPECT scan was normal in this case, our data suggest that this modality may be insensitive to this disorder.
Table 3. Significant associations between neuropsychological test scores and rCBF.

\begin{tabular}{ll}
\hline Test & ROI \\
\hline WAIS-R IQ & \\
VIQ & RASP $(r=0.77, P<0.01)$ \\
PIQ & LASP $(r=0.66, P<0.05)$ \\
FSIQ & RASP $(r=0.64, P<0.05)$ \\
\hline
\end{tabular}

\section{CALIFORNIA VERBAL LEARNING TEST}

Immediate memory

$\begin{array}{ll}\text { LPIP } & (r=0.84, P<0.05) \\ \text { LPSP } & (r=0.94, P<0.01) \\ \text { LPIP } & (r=0.85, P<0.05) \\ \text { LPIP } & (r=0.85, P<0.05)\end{array}$

$\begin{array}{ll}\text { Short delay recall } & \text { LPIP } \quad(r=0.85, P<0.05) \\ \text { Long delay recall }\end{array}$

\section{MANIPULATION OF ACQUIRED KNOWLEDGE}

\begin{tabular}{ll} 
Information & LPSP $(r=0.85, P<0.01)$ \\
Arithmetic & RAIF $(r=0.71, P<0.05)$ \\
& RASP $(r=0.81, P<0.01)$ \\
& R hemisphere $(r=0.63, P<0.05)$ \\
\hline
\end{tabular}

\section{Conclusion}

The distribution of cortical dysfunction based upon SPECT perfusion deficits showed characteristic patterns that were in agreement with the clinical diagnosis in 24 of 26 patients with dementia. In 3 patients rCBF SPECT findings were essential in reaching the final diagnosis when two clinical differential diagnoses were entertained. This series underscores the importance of this procedure in the differential diagnosis of dementing disorders. The relative quantitative data suggest that SPECT imaging is a useful procedure for in-vivo research of brain-behaviour relationships by providing a detailed perfusion map of the brain. This technique may also be very useful for identifying specific regions for cerebral biopsy, particularly when the brain is asymmetrically involved, as was the case in 4 AD patients in this study.

We found significant correlation between language impairment and left hemisphere perfusion deficits. This is in agreement with the findings by Burns et al. ${ }^{20}$ in their series of 20 patients. Although they used a different quantification method with 10 ROIs, they also found a correlation between language dysfunction and left frontal, left temporal, and left posterior parietal perfusion deficits. Correlation between reduced tracer uptake and language impairment has also been reported in other studies. ${ }^{21,22}$

The correlation between ideomotor apraxia and hypoperfusion in the left parietal region was significant. This is again in agreement with the findings reported by others. ${ }^{20}$ However, considering the number of variables involved in the statistical analyses, one must be cautious in interpreting the results. Replication of these results using larger samples are required in this regard.

The present study suggests that SPECT can provide important functional information to assist in understanding the anatomy underlying brain-behaviour relationships, as well as in the diagnosis of dementia.

\section{ACKNOWLEDGEMENTS}

This study was supported in part by a Career Scientist Award from the Ministry of Health of Ontario to Dr. Morris Freedman.

We gratefully acknowledge Vicki Giardino and Lynn Jeske for secretarial assistance. 


\section{REFERENCES}

1. Kung HK, Pan S, Kung M-P, et al. In vitro and in vivo evaluation of [123] I]IBZM: a potential CNS D-2 dopamine receptor imaging agent. J Nucl Med 1989; 30: 88-92.

2. Holman BL, Gibson RE, Hill TC, et al. Muscarinic acetylcholine receptors in Alzheimer's disease: in vivo imaging with iodine123-labelled 3-quinuclidinyl-4-iodobenzilate and emission tomography. JAMA 1985; 254: 3063-3066.

3. Sokoloff L. Relationship among local functional activity, energy metabolism and blood flow in central nervous system. Fed Proc 1981; 40: 2311-2316.

4. Hellman RS, Tikofsky RS, Collier BD, et al. Alzheimer disease: quantitative analysis of 1-123-iodoamphetamine SPECT brain imaging. Radiology 1989; 172: 183-188.

5. Gemmell HG, Sharp PF, Besson JA, et al. Differential diagnosis in dementia using the cerebral blood flow agent ${ }^{99 m}$ Tc HM-PAO: a SPECT study. J Comput Assist Tomogr 1987; 11: 398-402.

6. Neary D, Snowden JS, Shields RA, et al. Single photon emission tomography using ${ }^{99 \mathrm{~m} T c}$-HM-PAO in the investigation of dementia. I Neurol Neurosurg Psychiatry 1987; 50: 1101-1109.

7. Sharp P, Gemmell H, Cherryman G, et al. Application of iodine123-labelled isopropylamphetamine imaging to the study of dementia. J Nucl Med 1986; 27: 761-768.

8. Reed BR, Jagust W-J, Seab P, et al. Memory and regional cerebral blood flow in mildly symptomatic Alzheimer's disease. Neurology 1989; 39: 1537-1539.

9. Jagust W-J, Reed BR, Seab JP, et al. Clinical-physiologic correlates of Alzheimer's disease and frontal lobe dementia. Am J Physiol Imaging 1989; 4: 89-96.

10. Jagust W-J, Budinger TF, Reed BR. The diagnosis of dementia with single photon emission computed tomography. Arch Neurol 1987; 44: 258-262.

11. Friedland RP, Jagust WJ, Huesman RH, et al. Regional cerebral glucose transport and utilization in Alzheimer's disease. Neurology 1989; 39: 1427-1434.

12. DeKosky ST, Shih WJ, Schmitt FA, et al. Assessing utility of single photon emission computed tomography (SPECT) scan in Alzheimer disease: correlation with cognitive severity. Alzheimer Dis Assoc Disord 1990; 4: 14-23.

13. Holman BL. Perfusion and receptor SPECT in the dementias. George Taplin memorial lecture. J Nucl Med 1986; 27: 855-860.

14. Podreka I, Suess E, Goldenberg G, et al. Initial experience with technetium $99 \mathrm{~m}$ HM-PAO brain SPECT. J Nucl Med 1987; 28: 1657-1666.

15. Chase TN, Foster NL, Fedio P, et al. Regional cortical dysfunction in Alzheimer's disease as determined by positron emission tomography. Ann Neurol 1984; 15 (Suppl): S170-S174.

16. Kuhl DE, Barrio JR, Huang SC. Quantifying local cerebral blood by n-isopropyl-p(I123) iodoamphetamine (IMP) tomography. J Nucl Med 1986; 23: 196-203.

17. Knapp WH, von Kummer R, Kubler W. Imaging of cerebral blood flow-to-volume distribution using SPECT. J Nucl Med 1986; 27 : 465-470.

18. Spreafico G, Gadola G, Cammelli F, et al. Semiquantitative assessment of regional cerebral perfusion using $99 \mathrm{mTc} \mathrm{HM}-\mathrm{PAO}$ and emission tomography. Eur J Nucl Med 1988; 14: 565-568.

19. Kushner M, Tobin M, Alavi A, et al. Cerebellar glucose consumption in normal and pathologic states using fluorine-FDG and PET. J Nucl Med 1987; 28: 1667-1670.

20. Burns A, Philpot MP, Costa DC, et al. The investigation of Alzheimer's disease with single photon emission tomography. J Neurol Neurosurg Psychiatry 1989; 52: 248-253.

21. Perani D, Di Piero V, Vallar G, et al. Technetium-99m HM-PAOSPECT study of regional cerebral perfusion in early Alzheimer's disease. J Nucl Med 1988; 29: 1507-1514.

22. Montaldi D. Brooks DN, McColl JH, et al. Measurements of regional cerebral blood flow and cognitive performance in Alzheimer's disease. J Neurol Neurosurg Psychiatry 1990; 53: 33-38.

23. Cummings JL, Benson DF. Dementia: A Clinical Approach. Boston, Butterworths, 1983: 1 .

24. McKhann G, Drachman D, Folstein M, et al. Clinical diagnosis of Alzheimer's disease: Report of NINCOS-ADRDA Work Group under auspices of Department of Health and Human Services Task Force on Alzheimer's disease. Neurology 1984; 34: 939-944.
25. Rosen WG, Terry RD, Fuld PA, Katzman R, Peck A. Pathological verification of Ischemic Score in differentiation of dementias. Ann Neurol 1980; 7: 486-488.

26. Chang L-T. A method for attenuation correction in radionuclide computed tomography. IEEE Trans Nucl Sci 1978; NS-25: 638-643.

27. Johnson KA, Mueller ST, Walshe TM, English RJ, Holman BL. Cerebral perfusion imaging in Alzheimer's disease. Use of single photon emission computed tomography and iofetamine hydrochloride I 123. Arch Neurol 1987; 44: 165-168.

28. Cohen MB, Lake RR, Graham LS, et al. Quantitative iodine-123 IMP imaging of brain perfusion in schizophrenia. J Nucl Med 1989; 30:1616-1620.

29. Kretschmann HJ, Weinrich W. Neuroanatomy and Cranial Computed Tomography. New York: Thieme Inc., 1986: 18-45.

30. Haxby JV, Duara R, Grady CL, et al. Relations between neuropsychological and cerebral metabolic asymmetries in early Alzheimer's disease. J Cereb Blood Flow Metab 1985; 5: 193-200.

31. Foster NL, Chase TN, Fedio P, et al. Alzheimer's disease: focal cortical changes shown by positron emission tomography. Neurology 1983; 33: 961-965.

32. Brun A, Englund E. Regional pattern of degeneration in Alzheimer's disease: neuronal loss and histopathological grading. Histopathology 1981; 5: 549-564.

33. Ackerman RH, Alpert NM, et al. Correlation of positron emission scans with CT scans and clinical course. Acta Neurol Scand 1979; 60: 230-231.

34. Maurer AH. Nuclear medicine: SPECT comparisons to PET. Radiol Clin North Am 1988; 26: 1059-1074.

35. Pappata S, Tran Dinh S, Baron JC, et al. Remote metabolic effects of cerebrovascular lesions: magnetic resonance and positron tomography imaging. Neuroradiology 1987; 29: 1-6.

36. Kamo H, McGeer R, Harrop R, et al. Positron emission tomography and histopathology in Pick's disease. Neurology 1987; 37: 439-445.

37. McGeachie RE, Fleming JO, Sharer LR, et al. Case report: diagnosis of Pick's disease by computed tomography. J Comput Assist Tomogr 1979; 3: 113-115.

38. Wechsler AF, Verity MA, Rosenchein S, et al. Pick's disease: a clinical, computed tomographic, and histological study with Golgi impregnation observations. Arch Neurol 1982; 39: 287-290.

39. Tobo M, Fujii I, Hoaki T. Computed tomography in Pick's disease. Folia Psychiatr Neurol Jpn 1984; 38: 137-141.

40. Goodglass H, Kaplan E. The Assessment of Aphasia and Related Disorders. Philadelphia: Lea \& Febiger, 1983: 29-56.

41. Derouesne C, Rancurel G, Le Poncin Lafitte M, et al. Variability of cerebral blood flow defects in Alzheimer's disease on 123 iodo isopropyl-amphetamine and single photon emission tomography. Lancet 1985; 1: 1282.

42. Hachinski VC, Iliff LD, Zilkh E, et al. Cerebral blood flow in dementia. Arch Neurol 1975; 32: 632-637.

43. Kuhl DE, Metter EJ, Tieger WH, et al. Effects of human aging on patterns of local cerebral glucose utilization determined by the $\left[{ }^{18} \mathrm{~F}\right]$ fluorodeoxyglucose method (abst). J Cereb Blood Flow Metab 1987; 7 (Suppl 1): S411.

44. Chawluk JB, Alavi A, Jamieson DG, et al. Changes in local cerebral glucose metabolism with normal aging. the effects of cardiovascular and systemic health factors [abst]. J Cereb Blood Flow Metab 1987; 7 (Suppl): S411.

45. de Leon MJ, George AE, Tomanelli J, et al. Positron emission tomography studies of normal aging, a replication of PET III and 18-FDG using PET VI and 11-CDG. Neurobiol Aging 1987; 8 : 319-323.

46. Chawluk JB, Alavi A, Hurtig H, et al. Altered patterns of regional cerebral glucose metabolism in aging and dementia. J Cereb Blood Flow Metab 1985; 5: S121-S122.

47. Yoshii F, Barker WW, Chang JY, et al. Sensitivity of cerebral glucose metabolism to age, gender, brain volume, brain atrophy, and cerebrovascular risk factors. J Cereb Blood Flow Metab 1988; 8: 654-661.

48. Alavi A, Dann R, Chawluk J, et al. Positron emission tomography imaging of regional cerebral glucose metabolism. Semin Nucl Med 1986; 16: 2-34.

49. Mesulam MM. Slowly progressive aphasia without generalized dementia. Ann Neurol 1982; 11: 592-598.

50. Lee A, Mena IG, Miller B. Cerebral hypoxic injury detected by Tc-HMPAO SPECT. Clin Nucl Med 1989; 14: 482-483. 